\title{
Patient delay in the diagnosis of tuberculosis in Ethiopia: a systematic review and meta-analysis
}

\author{
Muluneh Alene $^{1 *} \mathbb{D}$, Moges Agazhe Assemie ${ }^{1}$, Leltework Yismaw', Getnet Gedif', Daniel Bekele Ketema',
} Wodaje Gietaneh ${ }^{1}$ and Tadele Demilew Chekol $^{2}$

\begin{abstract}
Background: Delay in the diagnosis of Tuberculosis (TB) remains a major challenge against achieving effective TB prevention and control. Though a number of studies with inconsistent findings were conducted in Ethiopia; unavailability of a nationwide study determining the median time of patient delays to TB diagnosis is an important research gap. Therefore, this study aimed to determine the pooled median time of the patient delay to TB diagnosis and its determinants in Ethiopia.

Methods: We followed PRISMA checklist to present this study. We searched from Google Scholar, PubMed, Science Direct, Web of Science, CINAHL, and Cochrane Library databases for studies. The comprehensive search for relevant studies was done by two of the authors (MA and LY) up to the 10th of October 2019. Risk of bias was assessed using the Newcastle-Ottawa scale adapted for observational studies. Data were pooled and a random effect metaanalysis model was fitted to provide the overall median time of patient delay and its determinants in Ethiopia. Furthermore, subgroup analyses were conducted to investigate how the median time of patient delay varies across different groups of studies.

Results: Twenty-four studies that satisfied the eligibility criteria were included. Our meta-analysis showed that the median time of the patient delay was 24.6 (95\%Cl: 20.8-28.4) days. Living in rural area (OR: 2.19, 95\%Cl: 1.51-3.18), and poor knowledge about TB (OR: 2.85, 95\%Cl: 1.49-5.47) were more likely to lead to prolonged delay. Patients who consult non-formal health providers (OR: 5.08, 95\%Cl: 1.56-16.59) had a prolonged delay in the diagnosis of TB. Moreover, the narrative review of this study showed that age, educational level, financial burden and distance travel to reach the nearest health facility were significantly associated with a patient delay in the diagnosis of TB.

Conclusions: In conclusion, patients are delayed more-than three weeks in the diagnosis of TB. Lack of awareness about TB, consulting non-formal health provider, and being in the rural area had increased patient delay to TB diagnosis. Increasing public awareness about TB, particularly in rural and disadvantaged areas could help to early diagnosis of TB.
\end{abstract}

Keywords: Delay, Median, Tuberculosis, Ethiopia, Meta-analysis

\footnotetext{
* Correspondence: mulunehadis@gmail.com

'Department of Public Health, Debre Markos University, Debre Markos, Ethiopia

Full list of author information is available at the end of the article
}

(c) The Author(s). 2020 Open Access This article is licensed under a Creative Commons Attribution 4.0 International License, which permits use, sharing, adaptation, distribution and reproduction in any medium or format, as long as you give appropriate credit to the original author(s) and the source, provide a link to the Creative Commons licence, and indicate if changes were made. The images or other third party material in this article are included in the article's Creative Commons licence, unless indicated otherwise in a credit line to the material. If material is not included in the article's Creative Commons licence and your intended use is not permitted by statutory regulation or exceeds the permitted use, you will need to obtain permission directly from the copyright holder. To view a copy of this licence, visit http://creativecommons.org/licenses/by/4.0/ The Creative Commons Public Domain Dedication waiver (http://creativecommons.org/publicdomain/zero/1.0/) applies to the data made available in this article, unless otherwise stated in a credit line to the data. 


\section{Background}

In 2017, an estimated 1.6 million people died due to treatable and curable disease called tuberculosis (TB) [1]. It is one of the top ten causes of death worldwide, and over $95 \%$ of cases and deaths are occurring in developing countries [2]. Though Ethiopia has achieved the reduction of TB incidence by halve, the decline of its incidence and prevalence rates has been comparatively slow [3].

In developing countries, delay in the diagnosis of TB remains a major challenge against effective management of the disease. Previous report showed that $42 \%$ patients are delayed to TB treatment in low-and middle-income countries [4]. Delay in seeking care worsen the burden of TB and the cost of care for patients, families and the overall public health system [5]. Patient-level and system-level barriers including limited knowledge, attitude, belief regarding TB, economic burdens, centralization of services, health system delays, and geographical access to healthcare influenced timely TB treatment initiation and compliances $[6,7]$.

The average time of patient delay in the diagnosis of $\mathrm{TB}$ and its determinants were reported by a number of studies [8-22]. However, the reported average time and determinant factors in these fragmented studies vary depending on the characteristics of study participants, the type of design employed and the variables analyzed. Having conclusive evidence by combining the existing studies is significant to have quality evidence on the national TB prevention and control program. Thus, this systematic review and meta-analysis aimed to determine the pooled median time of delay in the diagnosis of TB patients and to identify its determinants. This finding will help health-policy makers and other concerned body to apply efficient interventions, and to improve the health care seeking behavior of TB patients.

\section{Methods}

\section{Study design and setting}

A study that aimed to estimate the pooled median time of patient delay in the diagnosis of TB and to identify its determinants was conducted in Ethiopia. The country is subdivided into ten national regional states: namely Amhara, Tigray, Oromia, Afar, Benishangul-Gumuz, Somali, Southern Nations Nationalities and People Region (SNNPR), Sidama, Gambella, Harari, and two city administrative states (Dire Dawa city council and Addis Ababa city administration).

\section{Eligibility criteria}

\section{Criteria for including studies}

Study design All health facility-based cross-sectional studies reporting a patient delay in the diagnosis of pulmonary TB.
Study setting All studies reporting a patient delay in the diagnosis of pulmonary TB conducted in Ethiopia.

Participants All smear positive and negative pulmonary TB patients.

Outcome Studies which report the median time of patient delay for TB diagnosis.

Articles Published and unpublished studies.

\section{Criteria for excluding studies}

We excluded articles that were not fully accessed after at least two email contacts of the principal investigator.

\section{Searching for studies}

We followed the Preferred Reporting Items for Systematic Reviews and Meta-Analysis (PRISMA) checklist to present this study [23]. The comprehensive search for potential studies was conducted by two of the authors (MA and LY) up to the 10th of October 2019 without limitation to the year of publication. Two experienced review authors (MA and LY) searched from Google Scholar, Science Direct, PubMed, Cochrane library, Web of Science, and CINAHL databases for studies. The search from the above stated databases was performed using the following keywords: "patient delay" OR "total delay" AND "determinants" OR "factors" AND "Ethiopia".

\section{Outcome measures and data extraction}

Patient delay in the diagnosis of TB is the outcome variable of this study. It is the time from symptom onset to first consultation of the formal health system. Symptom onset referred to the time at which the first symptom such as chronic cough, fever, weight loss and night sweats of the illness began. Furthermore, the patient delay was categorized using a median cutoff point of 30 days. That is, greater than 30 days was taken as a prolonged patient delay. All relevant information from the included studies were extracted independently by two (MA and MAA) of authors after data extraction checklist development. It includes; the last name of the first author, publication year, the region of the study conducted, data collection period, study population, sample size, response rate, and median time of patient delay [24].

\section{Quality assessment tool}

Two reviewers (MA and DBK) assessed the quality of articles before inclusion to maintain methodological validity. The Newcastle-Ottawa Scale adapted for crosssectional studies was used to assess the risk of bias [25]. The tool organized in three sections with a maximum of ten score. The first section scored a maximum of five stars and focuses on the representativeness of the 
sample. The second section concerned on how the confounding variables controlled with a maximum of two stars. The third section is focused with the outcomes and statistical analysis of study with a possibility of three stars to be gained.

Finally, the average score provided by two reviewers was taken. Articles scored seven and above were considered as achieving high quality. This cut-off point was considered after referring previous literature [26].

\section{Data processing and analysis}

All relevant information was extracted using Microsoft excel software. $\mathrm{R}$ statistical software employed for metaanalysis. We used the quintile estimation method to estimate the overall medians time among the included studies. This approach had considerably lower absolute percent error than pooled means estimated via transformation-based approaches [27]. Bowley's coefficient of skewness $(\mathrm{SKb})$ was used to measure the skewness of data and if the mean $S K b$ greater than 0.1 median-based approaches are suggested.
We also conducted a meta-analysis on factors of patients delay in the diagnosis of TB. Since most of the included studies reported that the median patient delay was 30 days, we used it as a cut of point to dichotomize patient's delay. Moreover, subgroup analyses were conducted to investigate how the median of patient delay in the diagnosis of $\mathrm{TB}$ varies across different subgroups of the studies. The region of study conducted, year of publication, and the number of study participants incorporated are subgroups studied in this review.

\section{Results}

\section{Search results}

Figure 1, shows the number of literature searched, study selection, and the number of studies included. A total of 750 articles were identified during our search, and then 477 articles were excluded due to duplication. Twentyfour studies that satisfied the eligibility criteria were included in this systematic review and meta-analysis.

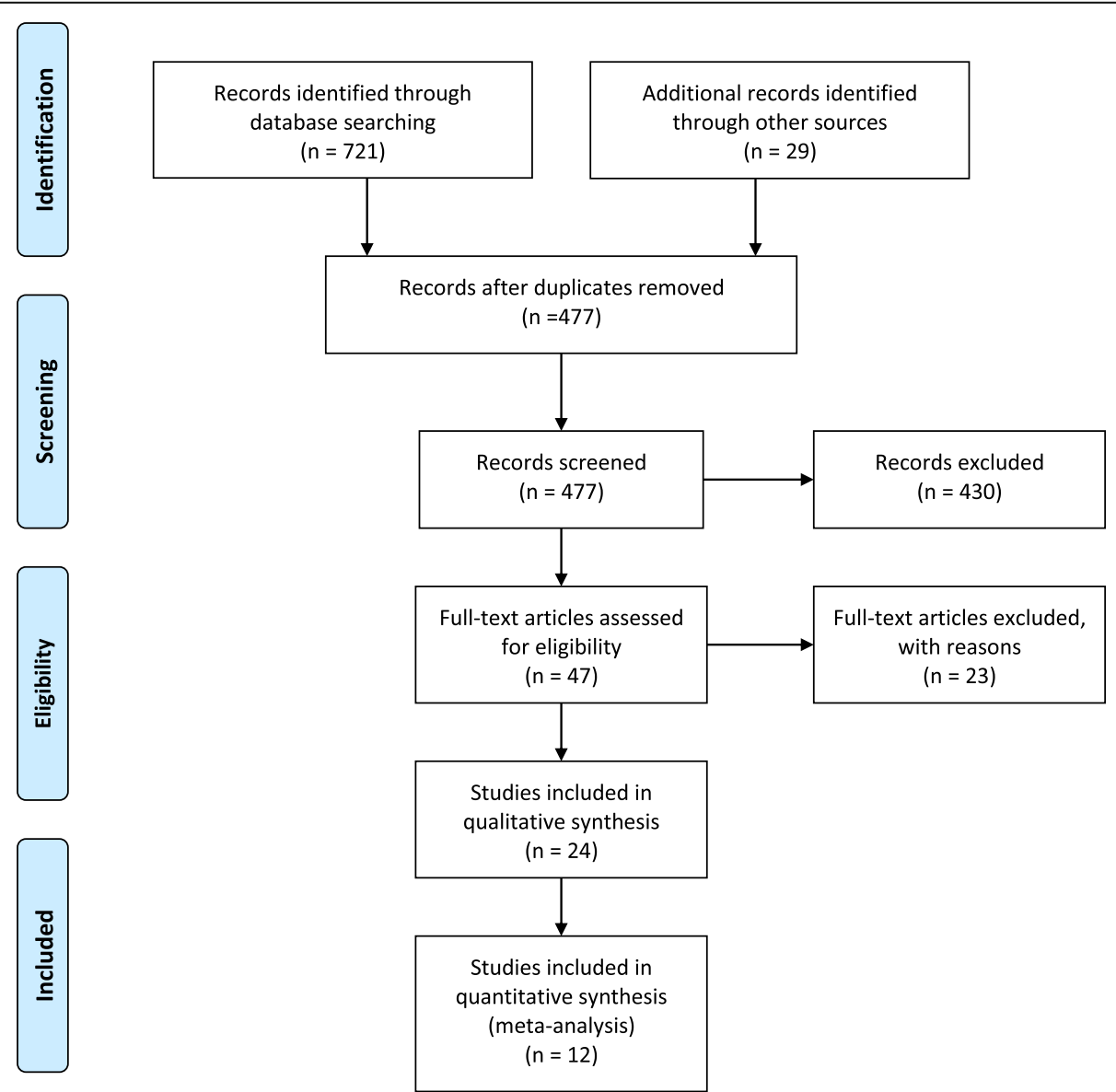

Fig. 1 Flow chart diagram describing the selection of studies included in the systematic review and meta-analysis of patient delay in diagnosis of tuberculosis in Ethiopia 


\section{Description of the included studies}

In this study, we included a total of twenty-four articles (Table 1). All the included studies were institutionalbased cross-sectional. Administratively, nine (41.7\%) studies were conducted in the Amhara region, four studies in Oromia region, three studies in South Nations Nationalities and Peoples Regions (SNNPR), and two studies in Addis Ababa. The publication year of the included studies was between 2002 and 2019. The number of study participants among included studies ranged from 105 to 735 . The smallest reported median time of the patient delay in the diagnosis of TB was 17 days [28], while the highest was 63 days [8]. Two-third (66.67\%) of the included studies had a high quality (Table S1).

\section{Magnitude of patient delay in the diagnosis of TB}

To pool the median time of the patient delay, we included studies that report the following summary measures; sample size, median, first quartile and third quartile. Finally, a total of twelve primary studies were included. The pooled median time of patient delay in the diagnosis of TB was 24.6 (95\%CI: 20.8-28.4) days.

Subgroup analysis was undertaken by the region of study conducted, publication year, sample size (below median versus above median), and the quality of the study.

The highest median time of the patient delay to $\mathrm{TB}$ diagnosis was reported in SNNPR (27.2 (95\%CI: 22.332.0)) days, while the smallest median time to TB diagnosis was observed in the Oromiya region $(15.0$ (95\%CI: 12.7-17.3)) days. Consequently, the overall median time of patient delay to TB diagnosis was 25.8 (95\%CI: 21.629.9) days among articles published before 2015 , while it was 24.3 (95\%CI: 18.0-30.5) days among articles published after 2015. In addition, the overall median time of the patient delay to TB diagnosis was 23.8 (95\% CI: $18.7-$ 28.9) days among articles included less-than 384 study participants, while it was 25.9 (95\%CI: 19.3-32.5) days among articles included 384 and above study participants (Table 2).

\section{Determinants of patient delay in the diagnosis of TB}

Significant determinants of patient delay in the diagnosis of TB among the included studies were presented in (Table S2). Fourteen studies examined the association between residence and patient delay in the diagnosis of TB. Consequently, a significant association between residence and patient delay was reported by eight studies [8-15]. Patients living in the rural area had prolonged delay compared to patients living in urban area. Our meta-analysis also revealed that patients from rural area were more likely to have a prolonged delay (OR: 2.19, 95\%CI: 1.51-3.18) (Fig. 2). Among nine studies that examine the association between knowledge about TB and patients delay, a significant result was reported by six studies [9, 11, 12, 16-18]. Our pooled analysis showed that patient delay is more likely among patients who had poor knowledge about TB (OR: 2.85, 95\%CI: 1.49-5.47) (Fig. 3). Moreover, this meta-analysis showed that seeking treatment from non-formal providers was a significant risk factor for longer health care-seeking delay of TB (OR: 5.08, 95\%CI: 1.56-16.59) (Fig. 4).

A significant association between the age of patient and prolonged delay was reported by five studies [17-20, 37]. Younger age group had a shorter time of TB diagnosis. In addition, a significant association between the educational level of a patient and patient delay was reported by five studies $[8,10,13,21,22]$. Consequently, as the educational level of the patient increases the likelihood of patient delay to TB diagnosis will be decreased. The other important variable which shows significant association to patient delay was time to reach the nearest health facility $[8,9,11,18,22,28,37]$. As the time elapses to reach the formal health provider increase, patients are more likely to have a prolonged delay. From the included studies, three studies reported that financial problem $[9,13,16]$ was associated with patient delay to diagnosis. Participants who had better economic status are less likely to have prolonged delays.

\section{Discussion}

This study was conducted to determine the pooled median time of patient delay in the diagnosis TB and to identify its determinants. The median time of patient delay among the included studies ranged from 17 to 63 days. The meta-analysis showed that the overall median time of patient delay in Ethiopia was 24.6 (95\%CI: 20.828.4) days. This result is comparable with other studies conducted in Tanzania, Uganda and India [38-40]. On the other hand, the median time of patient delay obtained in this study was shorter than previous studies conducted Mozambique, Angola and Ghana [41-43], and higher than studies conducted in Cameroon and China $[44,45]$. The possible explanation for this inconsistency might be differences in the socio-economic and demographic characteristics of study participants [46, 47]. The subgroup analysis by year of publication showed that the median time of patient delay among articles published after 2015 was shorter than articles published prior to 2015. This could be due to changes in policy and guidelines. In addition, a longer median time of patient delay was observed among studies with larger sample size $(\geq 384)$ than studies with smaller sample size $(<384)$.

The pooled result of this study revealed that patients living in rural area were more likely to have a prolonged delay. This finding is consistent with a study conducted in Nigeria [48]. This might be due to the shortage of formal health providers in rural area of Ethiopia [49]. Long 
Table 1 Characteristics of the included studies conducted in Ethiopia on patients delay in Tuberculosis diagnosis

\begin{tabular}{|c|c|c|c|c|c|c|c|c|}
\hline $\begin{array}{l}\text { First } \\
\text { author } \\
\text { (publication year) }\end{array}$ & Region & Data collection period & Study population & $\begin{array}{l}\text { Sample } \\
\text { size }\end{array}$ & $\begin{array}{l}\text { Prolonged delay } \\
\text { classification } \\
\text { (days) }\end{array}$ & $\begin{array}{l}\text { Response } \\
\text { rate }\end{array}$ & Median (IQR) & $\begin{array}{l}\text { Prolonged } \\
\text { delay }(\%)\end{array}$ \\
\hline $\begin{array}{l}\text { Adenager et al. } \\
\text { (2017) [28] }\end{array}$ & $\begin{array}{l}\text { Addis } \\
\text { Ababa }\end{array}$ & $\begin{array}{l}\text { April to } \\
\text { June } 2012\end{array}$ & $\begin{array}{l}\text { Both SP and SN PTB } \\
\text { patients }\end{array}$ & 422 & $>21$ & $99.76 \%$ & $17(9-33)$ & $42.1 \%$ \\
\hline $\begin{array}{l}\text { Alema et al. (2019) } \\
\text { [16] }\end{array}$ & Tigray & $\begin{array}{l}\text { Nov. 1, } 2015 \text { to } \\
\text { Jan.30, } 2016\end{array}$ & new PTB patients & 422 & $>30$ & & $30(21-60)$ & \\
\hline $\begin{array}{l}\text { Asefa et al. (2014) } \\
\text { [29] }\end{array}$ & SNNPR & June to December 2012 & SPPTB patients & 328 & $>30$ & NR & $30(20.2-60)$ & $N R$ \\
\hline $\begin{array}{l}\text { Asres et al. (2017) } \\
\text { [17] }\end{array}$ & Amhara & April 8 to July 7, 2013 & $\begin{array}{l}\text { All newly diagnosed } \\
\text { TB patients }\end{array}$ & 605 & $>30$ & $100 \%$ & $45(3-425)$ & $53.4 \%$ \\
\hline $\begin{array}{l}\text { Asres et al. (2019) } \\
\text { [18] }\end{array}$ & SNNPR & $\begin{array}{l}\text { January } \\
\text { to December } 2015\end{array}$ & $\begin{array}{l}\text { all new SP, } \\
\text { SN and EPTB cases }\end{array}$ & 735 & $>25$ & NR & $25(15-36)$ & $N R$ \\
\hline $\begin{array}{l}\text { Belay et al. (2012) } \\
\text { [30] }\end{array}$ & Afar & $\begin{array}{l}\text { September } 2009 \text { and March } \\
2010\end{array}$ & $\begin{array}{l}\text { TB } \\
\text { patients }\end{array}$ & 216 & $>20$ & $78 \%$ & $20(8-60)$ & $76 \%$ \\
\hline $\begin{array}{l}\text { Bogale et al. (2017) } \\
\text { [31] }\end{array}$ & Amhara & February to May, 2016 & PTB cases & 296 & $N R$ & NR & $\begin{array}{l}\text { Mean, } \\
33.9(\mathrm{sd}=14)\end{array}$ & $N R$ \\
\hline $\begin{array}{l}\text { Demissie et al. (2002) } \\
\text { [32] }\end{array}$ & $\begin{array}{l}\text { Addis } \\
\text { Abeba }\end{array}$ & $\begin{array}{l}\text { August } 1 \text { to December 311, } \\
998\end{array}$ & Newly PTB patients & 700 & $>30$ & NR & 60 & NR \\
\hline Fuge et al. (2018) [9] & SNNRP & $\begin{array}{l}\text { May and } \\
\text { September, } 2016\end{array}$ & TB patients & 398 & $>21$ & 99.3 & $30(5-120)^{*}$ & $58.2 \%$ \\
\hline $\begin{array}{l}\text { Gebeyehu et al. } \\
\text { (2014) [10] }\end{array}$ & Amhara & January to April, 2013 & $\mathrm{SP}, \mathrm{SN}$ and EPTB & 376 & $>21$ & NR & $\begin{array}{l}\text { SP27(10-59) } \\
\text { SN } 30(9-65)\end{array}$ & NR \\
\hline $\begin{array}{l}\text { Gebreegziabher } \\
\text { et al. (2016) [19] }\end{array}$ & Amhara & Oct 2013 to Oct 2014. & All new PTB patients & 706 & $>30$ & NR & $18(8-34)$ & $N R$ \\
\hline $\begin{array}{l}\text { Getnet et al. (2019) } \\
\text { [11] }\end{array}$ & Somali & $\begin{array}{l}\text { between December } 2017 \\
\text { and October } 2018\end{array}$ & All PTB patients & 442 & $>30$ & NR & $\begin{array}{l}\text { For cases:50 } \\
\text { (40-72) } \\
\text { For controls: } \\
20(14-25)\end{array}$ & $48.87 \%$ \\
\hline $\begin{array}{l}\text { Hussen et al. (2012) } \\
\text { [8] }\end{array}$ & Oromiya & $\begin{array}{l}\text { February } \\
\text { to March } 2011\end{array}$ & $\begin{array}{l}\text { All pulmonary TB } \\
\text { patients }\end{array}$ & 129 & $>14$ & $96 \%$ & $\begin{array}{l}63(14-896)^{*} \\
*=\text { range }\end{array}$ & NR \\
\hline $\begin{array}{l}\text { Mekonnen et al. } \\
\text { (2014) [22] }\end{array}$ & Amhara & 10 March - 08 May 2012 & TB patients & 315 & NR & NR & $\begin{array}{l}30(3-270)^{*} \\
*=\text { range }\end{array}$ & $52.4 \%$ \\
\hline $\begin{array}{l}\text { Mesfin et al. (2005) } \\
\text { [33] }\end{array}$ & Tigray & NR & TB patients & 237 & $>21$ & NR & $\begin{array}{l}\text { SPPTB:90 } \\
\text { SNPTB:60 } \\
\text { EXTB: } 90\end{array}$ & NR \\
\hline Seid et al. (2018) [34] & Amhara & $\begin{array}{l}\text { April1, } 2016 \text { to January 30, } \\
2017\end{array}$ & TB patients & 382 & $>30$ & NR & $30(15-60)$ & $41 \%$ \\
\hline $\begin{array}{l}\text { Shiferaw et al. (2019) } \\
\text { [35] }\end{array}$ & Amhara & 01 to 30 December 2017 & All TB patients & 170 & $>21$ & $95.3 \%$ & $\begin{array}{l}\text { Mean: } 53.2 \\
( \pm 8.54)\end{array}$ & $59.9 \%$ \\
\hline $\begin{array}{l}\text { Tsegaye et al. (2016) } \\
\text { [12] }\end{array}$ & Amhara & $\begin{array}{l}\text { July } 1 \text { to September 30, } \\
2013\end{array}$ & All PTB patients & 528 & $>30$ & $99.1 \%$ & $36(36)$ & $62.3 \%$ \\
\hline $\begin{array}{l}\text { Wondimu et al. } \\
\text { (2007) [13] }\end{array}$ & Oromiya & $\begin{array}{l}\text { January 11, } 2006 \text { to April } \\
11,2006\end{array}$ & All PTB patients & 201 & NR & $99.5 \%$ & 28 & NR \\
\hline $\begin{array}{l}\text { Yarlagadda et al. } \\
\text { (2018) [36] }\end{array}$ & Oromiya & February 9 to $20 / 2015$ & All PTB patients & 105 & $>21$ & NR & 91 (mean) & $58.09 \%$ \\
\hline $\begin{array}{l}\text { Yimer et al. (2005) } \\
\text { [37] }\end{array}$ & Amhara & $\begin{array}{l}\text { September 1, } 2003 \text { and } \\
\text { December 31, } 2003\end{array}$ & $\begin{array}{l}\text { new smear positive } \\
\text { PTB patients }\end{array}$ & 384 & $>30$ & NR & $30(15-90)$ & NR \\
\hline $\begin{array}{l}\text { Yimer et al. (2014) } \\
\text { [14] }\end{array}$ & Amhara & January to August 2010 & All PTB patients & 201 & $>30$ & NR & $21(7-60]$ & $68.7 \%$ \\
\hline $\begin{array}{l}\text { Yirgu et al. (2017) } \\
\text { [20] }\end{array}$ & Oromiya & June to July 2014 & All PTB patients & 358 & $>14$ & $100 \%$ & $15(5-30)$ & \\
\hline $\begin{array}{l}\text { Zeleke et al. (2014) } \\
\text { [15] }\end{array}$ & SNNR & $\begin{array}{l}\text { March } 2013 \text { to February } \\
2014\end{array}$ & SPPTB patients & 221 & $>35$ & $98.6 \%$ & 35 & NR \\
\hline
\end{tabular}

SNNRP Southern nations, nationalities, and peoples' region, NR Not Report, SPPTB Smear positive pulmonary tuberculosis, SN smear negative, EPTB extra pulmonary tuberculosis

${ }^{*}=P<0.05$ (The $95 \% \mathrm{Cl}$ does not include one) 
Table 2 Subgroup analysis of studies included in meta-analysis on patient delay in diagnosis of pulmonary tuberculosis in Ethiopia $(n=12)$

\begin{tabular}{|c|c|c|c|c|}
\hline Subgroup & Number of included studies & Random effects $(95 \% \mathrm{Cl})$ & Test of heterogeneity $\left(I^{2}\right)$ & $\mathrm{p}$-value \\
\hline \multicolumn{5}{|l|}{ By region } \\
\hline Amhara & 6 & $26.8(20.9-32.6)$ & $90.6 \%$ & $<0.001$ \\
\hline SNNPR & 2 & $27.2(22.3-32.0)$ & $81.9 \%$ & $<0.001$ \\
\hline Addis Ababa & 1 & $17.0(15.0-18.9)$ & - & \\
\hline Oromiya & 1 & $15.0(12.7-17.3)$ & - & \\
\hline Afar & 1 & $20.0(14.6-25.4)$ & - & \\
\hline Tigray & 1 & $30.0(26.6-33.4)$ & - & \\
\hline \multicolumn{5}{|c|}{ By publication year } \\
\hline Before 2015 & 5 & $25.8(21.6-29.9)$ & $71.5 \%$ & $<0.001$ \\
\hline After 2015 & 7 & $24.3(18.0-30.5)$ & $97.8 \%$ & $<0.001$ \\
\hline \multicolumn{5}{|l|}{ By sample size } \\
\hline$<384$ & 6 & $23.8(18.7-28.9)$ & $90.2 \%$ & $<0.001$ \\
\hline$\geq 384$ & 6 & $25.9(19.3-32.5)$ & $97.5 \%$ & $<0.001$ \\
\hline Overall & & $24.6(20.8-28.4)$ & $94.9 \%$ & \\
\hline
\end{tabular}

distance travelling discourages tuberculosis treatment initiation [7]. In addition, previous reports revealed that in rural areas, the first action to illness is consulting traditional healers [50]. Furthermore, a study conducted in the rural area of Nigeria showed that about $84 \%$ of TB patients first consulting a non-formal health provider [48].

Our pooled analysis showed that patient delay is more likely among patients who had poor knowledge about TB. This result is comparable with a study conducted in Mozambique, Bangladesh, and India [42, 51, 52]. The reason for this result might be patients who have poor knowledge of TB believe that TB is acquired from evil and they seek traditional healers or religious leaders to be freed from evil spirits [53]. This meta-analysis showed that seeking treatment from non-formal providers was a significant risk factor for longer patient delay of TB. A comparable result was obtained from studies conducted in low and middle-income countries, Mozambique, Uganda and Tanzania [4, 40, 42, 54]. This might be due to low knowledge tuberculosis [47]. Number and type of non-formal provider first consulted were the most important risk factors for delay [38].

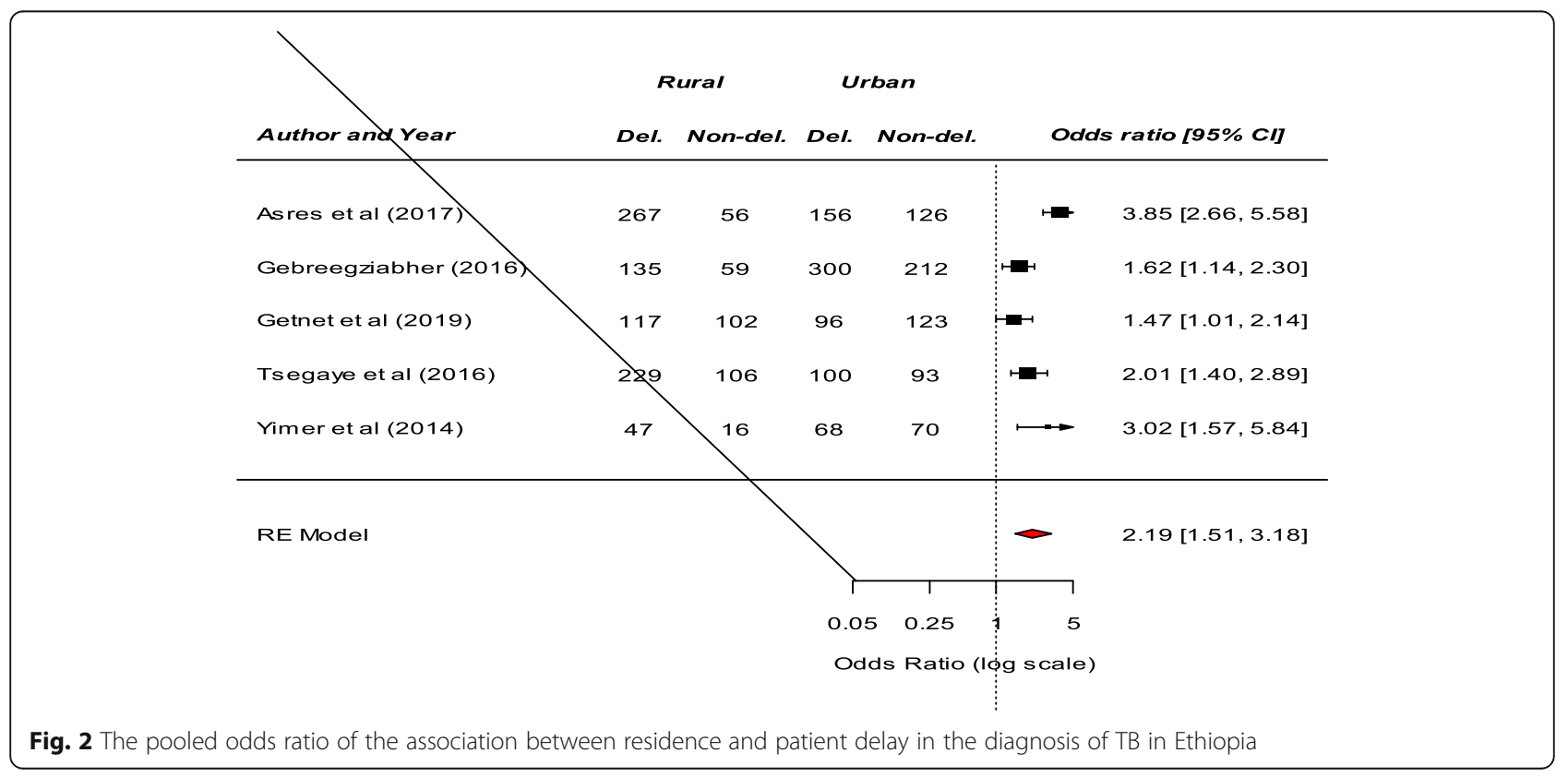




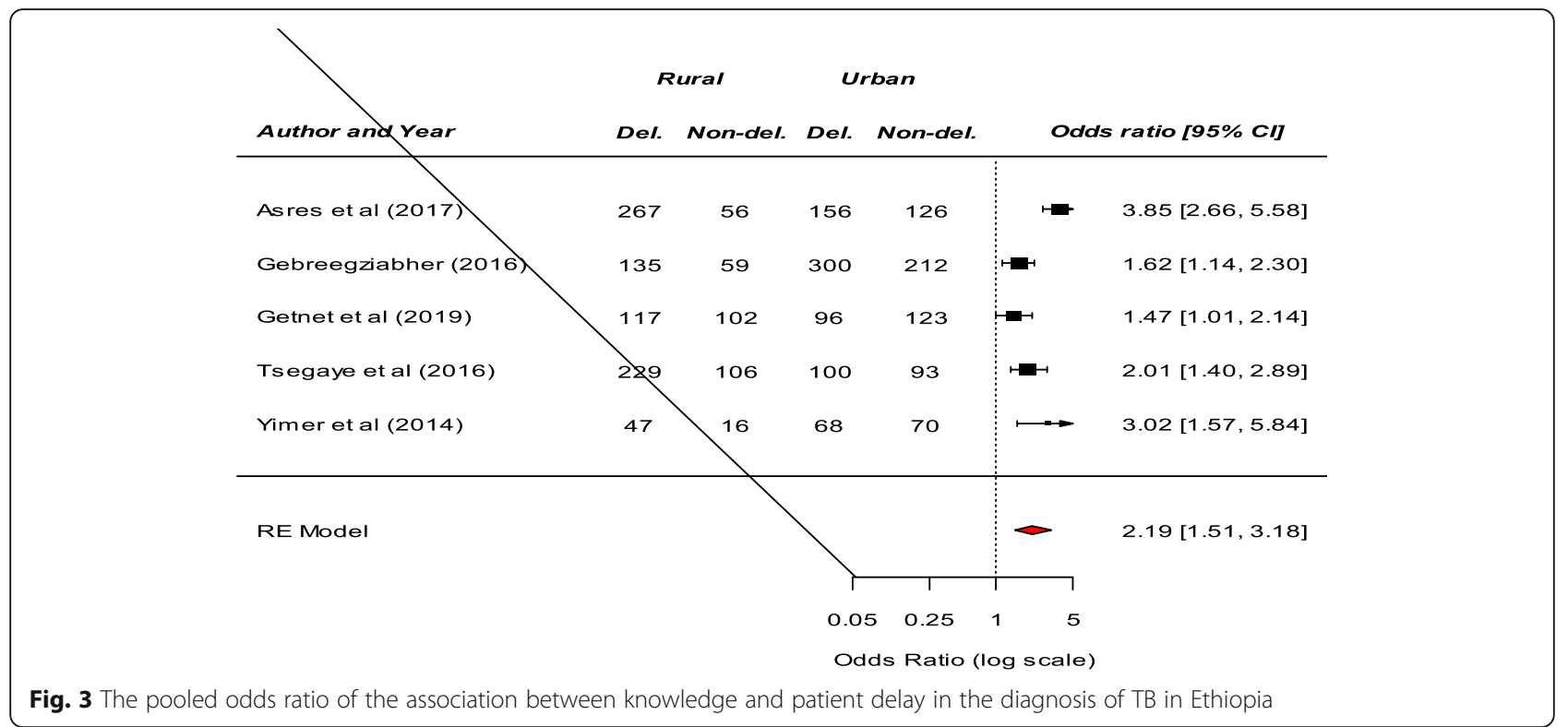

Due to inconsistent classification of age, we were unable to show the pooled effects. In two studies, patient delay was longer among study participants whose age are forty five and above $[19,37]$. The possible reason for this result might be older patients are dependent on others help and may not early seek health care. A study conducted in southern Ethiopia indicated that the health care seeking behaviors among elderly people is generally low [55].

Our narrative reviews also showed that the educational level of respondents was associated with patient delay in the diagnosis of TB. Consequently, as the educational level of patient increases the likelihood of patient delay to TB diagnosis will decreases, as found in few studies $[8,10,13,21]$. This result is supported by other studies conducted in South Africa [46]. The possible reason for this result might be study participants who had higher educational levels were more likely to be aware of $\mathrm{TB}$ than those who had no education [56].

In addition, as the time elapse to reach the formal health provider increase patients are more-likely to have prolonged delay $[8,9,11,18,28,37]$. This result is consistent with a study conducted in Angola and Uganda [41, 57]. A systematic review and meta-analysis study conducted in Asia revealed that long travel time to the nearest healthcare provider led to longer patient delays [58].

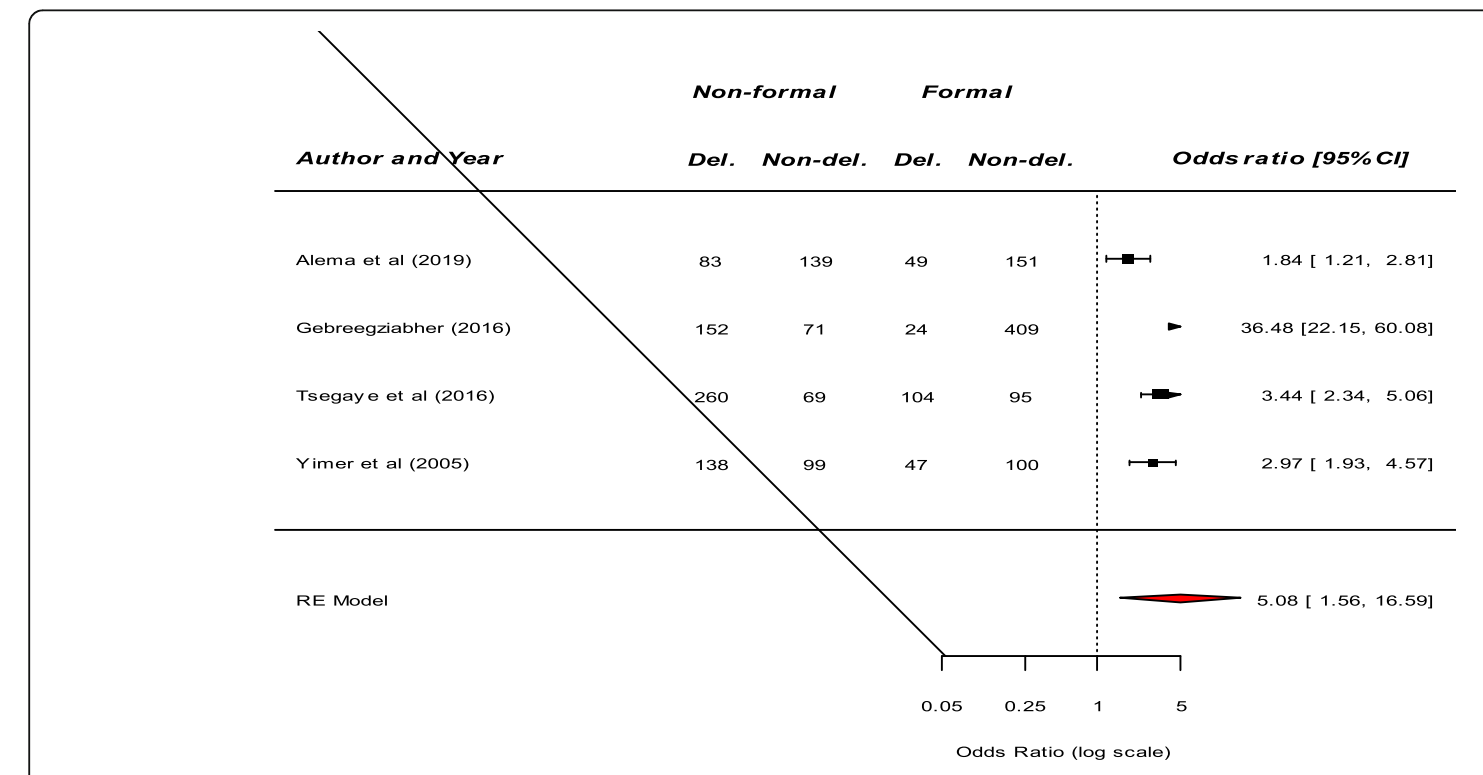

Fig. 4 The pooled odds ratio of the association between first action to illness and patient delay in the diagnosis of TB in Ethiopia 
Participants who had better economic status are lesslikely to have prolonged delay $[9,13,16]$. The possible explanation for this result might be patients suffered high economic losses prior to diagnosis [59]. The total median cost incurred from first consultation to diagnosis was $\$ 27$ per patient in Ethiopia [5].

\section{Limitations}

This systematic review and meta-analysis was not without limitations. Firstly, the review was limited to only articles published in the English language. Secondly, all of the included studies were institution based cross-sectional studies, which limits assessment of the cause-effect relationships. Thirdly, there is sizable in-consistency across the included studies. The observed heterogeneity might be described by the quality of the studies.

\section{Conclusions}

In conclusion, patients are delayed more-than three weeks in the diagnosis of TB. Lack of awareness about $\mathrm{TB}$, consulting non-formal health provider, and living in the rural area had increased patient delay to TB diagnosis. Increasing public awareness about $\mathrm{TB}$ and active case finding, particularly in rural and disadvantaged areas could help to early diagnosis of TB.

\section{Supplementary information}

Supplementary information accompanies this paper at https://doi.org/10. 1186/s12879-020-05524-3.

Additional file 1: Table S1. Assessing the risk of bias for the included studies.

Additional file 2: Table S2. Significant determinants of unintended pregnancy reported from each study.

\section{Abbreviations}

TB: Tuberculosis; PRISMA: Preferred Reporting Items for Systematic Reviews and Meta-Analysis

\section{Acknowledgements \\ Authors of primary study.}

\section{Authors' contributions}

MA1: Conception of research protocol, study design, literature review, data extraction, data analysis, interpretation and drafting the manuscript. MA2, LY, GG, DBK, and WG contribute on data extraction, quality assessment, data analysis and manuscript review and TDC edition \& validation. All authors have read and approved the manuscript.

\section{Funding}

Not applicable.

\section{Availability of data and materials}

All data are available in the manuscript.

\section{Ethics approval and consent to participate}

Not applicable.

\section{Consent for publication}

Not applicable.

\section{Competing interests}

The authors declare that they have no competing interests.

\section{Author details}

${ }^{1}$ Department of Public Health, Debre Markos University, Debre Markos, Ethiopia. ${ }^{2}$ School of Medicine, Debre Markos University, Debre Markos, Ethiopia.

Received: 19 February 2020 Accepted: 16 October 2020

Published online: 27 October 2020

\section{References}

1. Zumla A, Petersen E. The historic and unprecedented United Nations general assembly high level meeting on tuberculosis (UNGA-HLMTB)_' 'united to end TB: an urgent global response to a global epidemic'. Int J Infect Dis. 2018;75:118-20.

2. World Health organization. Global Tuberculosis Report 2017. 2017. Avaialable online at https://www.who.int/tb/publications/global_report/en. Accessed 3 Dec 2019.

3. Deribew A, Deribe K, Dejene T, Tessema GA, Melaku YA, Lakew Y, Amare AT, Bekele T, Abera SF, Dessalegn M, Kumsa A. Tuberculosis burden in Ethiopia from 1990 to 2016: evidence from the global burden of diseases 2016 study. Ethiopian journal of health sciences. 2018;28(5).

4. Getnet F, Demissie M, Assefa N, Mengistie B, Worku A. Delay in diagnosis of pulmonary tuberculosis in low-and middle-income settings : systematic review and meta- analysis. BMC Pulmon Med. 2017;17(1):202.

5. Mesfin MM, Newell JN, Madeley RJ, Mirzoev TN, Tareke IG, Kifle YT, Gessessew A, Walley JD. Cost implications of delays to tuberculosis diagnosis among pulmonary tuberculosis patients in Ethiopia. BMC Public Health. 2010;10(1):173.

6. Sullivan BJ, Esmaili BE, Cunningham CK. Barriers to initiating tuberculosis treatment in sub-Saharan Africa: a systematic review focused on children and youth. Glob Health Action. 2017;10(1):1290317.

7. Tadesse T, Demissie M, Berhane Y, Kebede Y, Abebe M. Long distance travelling and financial burdens discourage tuberculosis DOTs treatment initiation and compliance in Ethiopia : a qualitative study. BMC Public Health. 2013:13(1):424

8. Hussen A, Biadgilign S, Tessema F, Mohammed S, Deribe K, Deribew A. Treatment delay among pulmonary tuberculosis patients in pastoralist communities in bale zone, Southeast Ethiopia. BMC Res Notes. 2012;5(1): 320.

9. Fuge TG, Bawore SG, Solomon DW, Hegana TY. Patient delay in seeking tuberculosis diagnosis and associated factors in Hadiya zone, southern Ethiopia. BMC Res Notes. 2018:11(1):115.

10. Gebeyehu E, Azage M, Abeje G. Factors associated with patient's delay in tuberculosis treatment in Bahir Dar City administration, Northwest Ethiopia. BioMed Res Int. 2014;1:2014.

11. Getnet F, Demissie M, Worku A, Gobena T, Seyoum B, Tschopp R, Andersen $\mathrm{CT}$. Determinants of Patient Delay in Diagnosis of Pulmonary Tuberculosis in Somali Pastoralist Setting of Ethiopia: A Matched Case-Control Study. Int J Environ Res Public Health. 2019;16(18):3391.

12. Tsegaye D, Abiy E, Mesele T, et al. Delay in seeking health care and associated factors among pulmonary tuberculosis patients in north Wollo zone, Northeast Ethiopia: Institution Based Cross-sectional Study. Arch Clin Microbiol. 2016:7:3.

13. Wondimu T, Kassahun W, Getachew S. Delay in initiating tuberculosis treatment and factors associated among pulmonary tuberculosis patients in east Wollega, Western Ethiopia. Ethiop J Health Dev. 2007;21(2):148-56.

14. Yimer SA, Bjune GA, Holm-Hansen C. Time to first consultation, diagnosis and treatment of TB among patients attending a referral hospital in northwest, Ethiopia. BMC Infect Dis. 2014;14(1):19.

15. Zeleke ZZ, Trifa ZM. Treatment delay among smear positive pulmonary tuberculosis patients in South Ethiopia: a cross-sectional study. Sci J Public Health. 2014;2(5):402-9.

16. Alema HB, Hailemariam SA, Misgina KH, Weldu MG, Gebregergis YS, Mekonen GK, Gebremedhin KA. Health care seeking delay among pulmonary tuberculosis patients in north west zone of Tigrai region, North Ethiopia. BMC Infect Dis. 2019;19(1):309.

17. Asres M, Gedefaw M, Kahsay A, Weldu Y. Patients' delay in seeking health care for tuberculosis diagnosis in east Gojjam zone, Northwest Ethiopia. Am J Trop Med Hygiene. 2017;96(5):1071-5. 
18. Asres A, Jerene D, Deressa W. Delays to anti-tuberculosis treatment intiation among cases on directly observed treatment short course in districts of southwestern Ethiopia: a cross sectional study. BMC Infect Dis. 2019;19(1):481.

19. Gebreegziabher SB, Bjune GA, Yimer SA. Patients' and health system's delays in the diagnosis and treatment of new pulmonary tuberculosis patients in west Gojjam zone, Northwest Ethiopia: a cross-sectional study. BMC Infect Dis. 2016;16(1):673

20. Yirgu R, Lemessa F, Hirpa S, Alemayehu A, Klinkenberg E. Determinants of delayed care seeking for TB suggestive symptoms in Seru district, Oromiya region, Ethiopia: a community based unmatched case-control study. BMC Infect Dis. 2017;17(1):29.

21. Mesfin MM, Tasew TW, Tareke IG, Kifle YT, Karen WH, Richard MJ. Delays and care seeking behavior among tuberculosis patients in Tigray of northern Ethiopia. Ethiop J Health Dev. 2005;19(I):7.

22. Mekonnen YA, Abebe L, Fentahun N, Belay SA, Kassa AW. Delay for first consultation and associated factors among tuberculosis patients in Bahir Dar town administration, north West Ethiopia. Am J Health Res. 2014;2(4):140-5.

23. Moher D, Liberati A, Tetzlaff J, Altman DG, The PRISMA Group. Preferred reporting items for systematic reviews and Meta-analyses: the PRISMA statement. PLoS Med. 2009;6(7):e1000097. https://doi.org/10.1371/journal. pmed1000097.

24. Alene M, Yismaw L, Berelie $Y$, Kassie B, Yeshambel R, Assemie MA. Prevalence and determinants of unintended pregnancy in Ethiopia: a systematic review and meta-analysis of observational studies. PLoS One. 2020;15(4):e0231012

25. Newcastle-Ottawa Scale customized for cross-sectional studies In. available from https://static-content.springer.com/esm/../12889_2012_5111_ MOESM3_ESM.doc. Accessed 2 Dec 2019

26. Tekelab T, Chojenta C, Smith R, Loxton D. Factors affecting utilization of antenatal care in Ethiopia: a systematic review and meta-analysis. PLoS One. 2019;14(4):e0214848

27. McGrath S, Zhao X, Qin ZZ, Steele R, Benedetti A. One-sample aggregate data meta-analysis of medians. Stat Med. 2019;38(6):969-84.

28. Adenager GS, Alemseged F, Asefa H, Gebremedhin AT. Factors associated with treatment delay among pulmonary tuberculosis patients in public and private health facilities in Addis Ababa, Ethiopia. Tuberculosis research and treatment. 2017;2017.

29. Asefa A, Teshome W. Total delay in treatment among smear positive pulmonary tuberculosis patients in five primary health centers, southern Ethiopia: a cross sectional study. PloS one. 2014;9(7):e102884.

30. Belay M, Bjune G, Ameni G, Abebe F. Diagnostic and treatment delay among Tuberculosis patients in Afar Region, Ethiopia: a cross-sectional study. BMC public health. 2012;12(1):369.

31. Bogale S, Diro E, Shiferaw AM, Yenit MK. Factors associated with the length of delay with tuberculosis diagnosis and treatment among adult tuberculosis patients attending at public health facilities in Gondar town, Northwest, Ethiopia. BMC infectious diseases. 2017:17(1):145.

32. Demissie M, Lindtjorn B, Berhane Y. Patient and health service delay in the diagnosis of pulmonary tuberculosis in Ethiopia. BMC public health. 2002; 2(1):23.

33. Mesfin MM, Tasew TW, Tareke IG, Kifle YT, Karen WH, Richard MJ. Delays and care seeking behavior among tuberculosis patients in Tigray of northern Ethiopia. Ethiopian Journal of Health Development. 2005;19(I):7.

34. Seid A, Metaferia Y. Factors associated with treatment delay among newly diagnosed tuberculosis patients in Dessie city and surroundings, Northern Central Ethiopia: a cross-sectional study. BMC Public Health. 2018;18(1):931.

35. Shiferaw MB, Zegeye AM. Delay in tuberculosis diagnosis and treatment in Amhara state, Ethiopia. BMC health services research. 2019;19(1):232.

36. Yarlagadda R, Mulugeta T, Gashe F, Tatiparthi R. Delay for Treatment and Associated Factors among Tuberculosis Patients in Jimma Town, Ethiopia. ljppr. Human. 2018;13(4):1-18.

37. Yimer S, Bjune G, Alene G. Diagnostic and treatment delay among pulmonary tuberculosis patients in Ethiopia: a cross sectional study. BMC Infect Dis. 2005:5(1):112.

38. Sreeramareddy eCT, Qin ZZ, Satyanarayana S, Subbaraman R, Pai M. Delays in diagnosis and treatment of pulmonary tuberculosis in India: a systematic review. Int J Tuberc Lung Dis. 2014;18(3):255-66.

39. Said K, Hella J, Mhalu G, Chiryankubi M, Masika E, Maroa T, Mhimbira F, Kapalata N, Fenner L. Diagnostic delay and associated factors among patients with pulmonary tuberculosis in Dar Es Salaam, Tanzania. Infect Dis Poverty. 2017;6(1):64.
40. Buregyeya E, Criel B, Nuwaha F, Colebunders R. Delays in diagnosis and treatment of pulmonary tuberculosis in Wakiso and Mukono districts, Uganda. BMC Public Health. 2014;14(1):586.

41. Santos E, Felgueiras Ó, Oliveira O, Duarte R. Diagnosis delay of tuberculosis in the Huambo province, Angola. Pulmonology. 2018;24(5):294-9.

42. Saifodine A, Gudo PS, Sidat M, Black J. Patient and health system delay among patients with pulmonary tuberculosis in Beira city, Mozambique. BMC Public Health. 2013;13(1):559.

43. Osei $E$, Akweongo $P$, Binka F. Factors associated with DELAY in diagnosis among tuberculosis patients in Hohoe municipality, Ghana. BMC Public Health. 2015;15(1):721.

44. Cambanis A, Ramsay A, Yassin MA, Cuevas LE. Duration and associated factors of patient delay during tuberculosis screening in rural Cameroon. Tropical Med Int Health. 2007;12(11):1309-14.

45. Xu X, Liu JH, Cao SY, Zhao Y, Dong XX, Liang Y, Lu ZX. Delays in care seeking, diagnosis and treatment among pulmonary tuberculosis patients in Shenzhen, China. Int J Tuberc Lung Dis. 2013;17(5):615-20.

46. Christian C, Burger C, Claassens M, Bond V, Burger R. Patient predictors of health-seeking behaviour for persons coughing for more than two weeks in high-burden tuberculosis communities: the case of the Western cape, South Africa. BMC Health Serv Res. 2019;19(1):160.

47. Gelaw SM. Socioeconomic factors associated with knowledge on tuberculosis among adults in Ethiopia. Tuberc Res Treat. 2016;1:2016.

48. Ukwaja KN, Alobu I, Nweke CO, Onyenwe EC. Healthcare-seeking behavior, treatment delays and its determinants among pulmonary tuberculosis patients in rural Nigeria: a cross-sectional study. BMC Health Serv Res. 2013; 13(1):25.

49. Woldemichael A, Takian A, Sari AA, Olyaeemanesh A. Availability and inequality in accessibility of health Centre-based primary healthcare in Ethiopia. PLoS One. 2019;14(3):e0213896.

50. Finnie RK, Khoza LB, van den Borne B, Mabunda T, Abotchie P, Mullen PD. Factors associated with patient and health care system delay in diagnosis and treatment for TB in sub-Saharan African countries with high burdens of TB and HIV. Tropical Med Int Health. 2011;16(4):394-411.

51. Selvam Paramasivam BT, Chandran P, Thayyil J, George B, Sivakumar CP. Diagnostic delay and associated factors among patients with pulmonary tuberculosis in Kerala. J Fam Med Primary Care. 2017;6(3):643.

52. Mondal MN, Nazrul HM, Chowdhury MR, Howard J. Socio-demographic factors affecting knowledge level of tuberculosis patients in Rajshahi City, Bangladesh. Afr Health Sci. 2014;14(4):855-65.

53. Verhagen LM, Kapinga $R$, van Rosmalen-Nooijens KA. Factors underlying diagnostic delay in tuberculosis patients in a rural area in Tanzania: a qualitative approach. Infection. 2010;38(6):433-46.

54. Mhalu G, Weiss MG, Hella J, Mhimbira F, Mahongo E, Schindler C, Reither K, Fenner L, Zemp E, Merten S. Explaining patient delay in healthcare seeking and loss to diagnostic follow-up among patients with presumptive tuberculosis in Tanzania: a mixed-methods study. BMC Health Serv Res. 2019;19(1):217.

55. Falaha T, Worku A, Meskele M, Facha W. Health care seeking behaviour of elderly people in rural part of Wolaita zone, Southern Ethiopia. Health Sci J. 2016;10(4):1.

56. Luba TR, Tang S, Liu Q, Gebremedhin SA, Kisasi MD, Feng Z. Knowledge, attitude and associated factors towards tuberculosis in Lesotho: a population based study. BMC Infect Dis. 2019;19(1):96.

57. Fluegge K, Malone LL, Nsereko M, Okware B, Wejse C, Kisingo H, Mupere E, Boom WH, Stein CM. Impact of geographic distance on appraisal delay for active TB treatment seeking in Uganda: a network analysis of the Kawempe Community Health Cohort Study. BMC public health. 2018;18(1):798.

58. Cai J, Wang X, Ma A, Wang Q, Han X, Li Y. Factors associated with patient and provider delays for tuberculosis diagnosis and treatment in Asia: a systematic review and meta-analysis. PLoS One. 2015;10(3):e0120088.

59. Foster N, Vassall A, Cleary S, Cunnama L, Churchyard G, Sinanovic E. The economic burden of TB diagnosis and treatment in South Africa. Soc Sci Med. 2015;130:42-50.

\section{Publisher's Note}

Springer Nature remains neutral with regard to jurisdictional claims in published maps and institutional affiliations. 